\title{
Biodegradable hollow fibres for the controlled release of drugs
}

\author{
J.M. Schakenraad, J.A. Oosterbaan, P. Nieuwenhuis, I. Molenaar \\ Department of Histology and Centre for Medical Electronmicroscopy, University of Groningen, Oostersinge/ 69/2, 9713 EZ. \\ Groningen, The Netherlands \\ J. Olijslager \\ Plastics and Rubber Institute, TNO, Delft, The Netherlands
}

W. Potman, M.J.D. Eenink and J. Feijen

Department of Chemical Technology, University of Twente, PO Box 217, 7500 AE Enschede, The Netherlands

Presented at Biointeractions '87, Cambridge, UK in July 1987

Biodegradable hollow fibres of poly-L-lactic acid (PLLA) filled with a suspension of the contraceptive hormone levonorgestrel in castor oil were implanted subcutaneously in rats to study the rate of drug release, rate of biodegradation and tissue reaction caused by the implant. The in vivo drug release was compared with the release in vitro using different release media. Fibres, disinfected with alcohol showed a zero-order release, both in vitro and in vivo, for over 6 months. Fibres, either $\gamma$-sterilized or disinfected with alcohol were harvested at time intervals ranging from $1 \mathrm{~d}$ to 6 months after implantation. Molecular weights of PLLA, tensile strengths, and remaining amounts of drug were determined as a function of time.

The tissue reaction can be described as a very moderate foreign body reaction with the initial presence of macrophages, which are gradually replaced by fibroblasts which form a collagen capsule. Molecular weight determinations of PLLA showed a decrease from an initial $\bar{M}_{w}$ of $1.59 \times 10^{5}$ to $5.5 \times 10^{4}$ in 4 months (after alcohol sterilization). A gradual decrease in fibre strength with time was observed which did not significantly impair the release rate of levonorgestrel.

Keywords: Drugs, controlled release, hollow fibre, biodegradable, poly-L-lactic acid

The development of improved methods of drug delivery has received a lot of attention in the last two cecades. In many cases a constant effective non-toxic level of the drug at a particular body location is needed. To reach this goal many variations of controlled release have been investigated. These include the use of bioerodible matrices ${ }^{1,2}$ (from which the drug is released by controlled degradation of the top layers of the matrix), microspheres or even nanoparticles, with a polymer body, (from which the drug is slowly released) ${ }^{3}$ or controlled delivery by (mini) devices ${ }^{4}$.

The methods mentioned above may have one or more disadvantages e.g. (i) either no zero-order release can be achieved, (ii) the appliance cannot, or not easily, be removed in case of an emergency, (iii) an operation is needed to insert the device, (iv), the materials used are not optimally biocompatible.

Therefore a release system was developed with none of these disadvantages ${ }^{5-7}$ i.e. a hollow fibre of poly-L-lactic acid (PLLA) containing the drug suspended in oil from which it is released at a zero-order rate. Its dimensions $(1 \mathrm{~cm}$ long, diam. $0.7 \mathrm{~mm}$ ) allow a simple application, using a syringe.

Correspondence to $\mathrm{Dr}$ J.M. Schakenraad.
Removal of the fibre can easily be performed by a small incision, in case of an emergency.

In this paper we present the results of studies on the in vivo and in vitro release of levonorgestrel from hollow fibres, the rate of biodegradation of the fibre material, and the cell-biological evaluation as a response to the subcutaneous implantation of the fibre in rats.

\section{MATERIALS AND METHODS}

Fibres. The hollow fibres were spun from poly-L-lactic acid $\left(\bar{M}_{w} 159000\right)$ using a 'dry-wet' coagulation spinning process $^{5,6}$. The tube-in-orifice spinneret device contained an injection tube with an external diam. of $0.6 \mathrm{~mm}$, an internal diam. of $0.4 \mathrm{~mm}$, and an orifice diam. of $1.0 \mathrm{~mm}$. The spinning dope was composed of $80 \%$ dioxane, $15 \%$ poly-Llactic acid and $5 \%$ polyvinylpyrrolidine (PVP) at a temp. of $50^{\circ} \mathrm{C}$; water was used as the internal and external coagulant. The hollow fibres (Figure 1) obtained by this procedure (Batch no. 146-8) had an external diam. of $0.72 \mathrm{~mm}$, an internal diam. of $0.47 \mathrm{~mm}$ and a wall thickness of $0.13 \mathrm{~mm}$. The fibre consisted of a porous matrix with a dense nonporous skin (approx. $0.3 \mu \mathrm{m}$ ) on both sides. The fibres were 

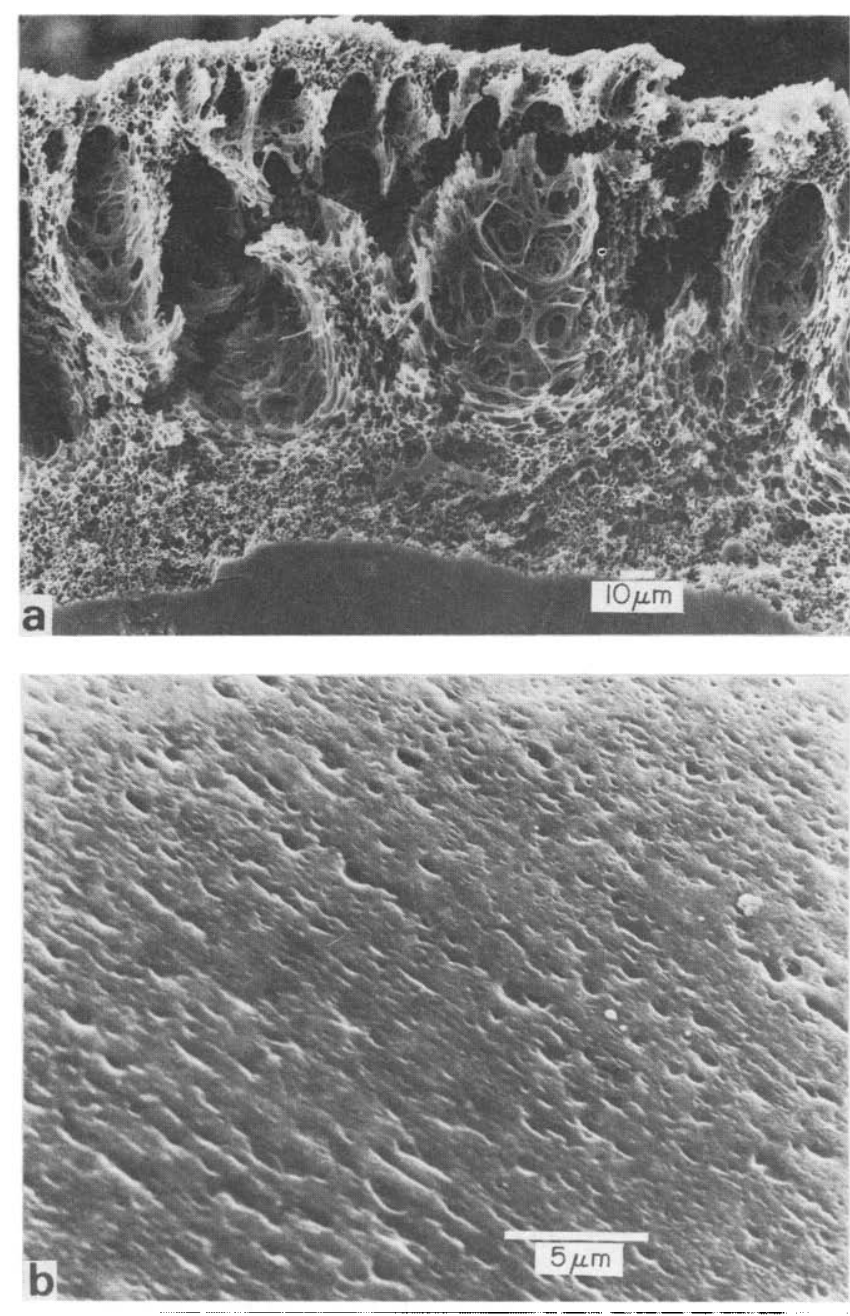

Figure 1 SEMs of (a) the fibre wall and (b) the outer surface

cut at a length of $1.4 \mathrm{~cm}$, filled with levonorgestrel suspended in castor oil $(25 \% \mathrm{w} / \mathrm{w})$ and heat-sealed at both ends. The effective length of the drug containing fibres was $1.0 \mathrm{~cm}$.

Experimental design. Poly-L-lactic acid fibres were examined empty, filled with castor oil or filled with levonorgestrel suspended in castor oil. For each series we determined in vivo, as a function of time: tissue reaction, tensile strength of the fibre, molecular weight of the PLLA, residual levonorgestrel (if relevant). At day 1 , day 2, day $4,1 w k, 2 w k, 3 w k$, 1 month, 2 months, 4 months, 6 months and for tensile strength and molecular weight determinations also at 12 months, 18 months and 24 months, fibres were harvested and examined for the previously mentioned parameters. For each parameter and time interval $n=6$.

Sterilization. Fibres were either $\gamma$-sterilized (2.5 Mrad) or disinfected with $70 \%$ alcohol, followed by drying in air.

Implantation procedure. The fibres were implanted subcutaneously in female $\mathrm{AO} / \mathrm{BN}$ rats approx. 3 months old weighing $200-250 \mathrm{~g}$. A specially adapted syringe (Figure 2) was used for this purpose. The rat was shaved on its back which was subsequently disinfected with alcohol, before the fibres were implanted. Six fibres were implanted per parameter and time interval. If fibres were empty or

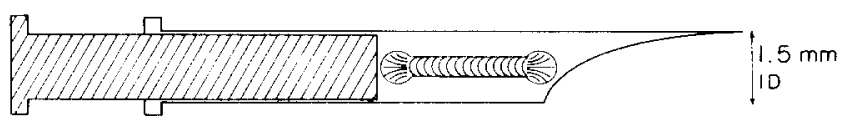

Figure 2 Syringe used for injecting hollow fibres. contained only castor oil, six fibres were implanted in one rat. If fibres contained levonorgestrel, two fibres were implanted in one rat.

Harvesting. At different harvesting times the rats were ether-anaesthetized and the fibres collected including the surrounding tissue. The fibres were immediately fixed in $2 \%$ glutaraldehyde in phosphate buffer $(0.1 \mathrm{M}, \mathrm{pH} 7.4)$ for determination of tissue reaction, or processed for determination of molecular weight, fibre strength or remaining fibre contents.

Tissue reaction. The fibres with adhering tissue were transversely vibratomized in $300 \mu \mathrm{m}$ sections and posttixed with Karnovsky fixative. Dehydration was performed in an alcohol series followed by butyl-2,3-epoxypropylether. Subsequently the specimens were embedded in Epon 10:1. More contrast could be obtained after staining en bloc with $2 \%(w / v)$ uranyl acetate in $10 \%(v / v)$ ethanol. Semi-thin sections $(1 \mu \mathrm{m})$ were cut and appropriate areas were selected for making ultrathin sections $(50 \mathrm{~nm})$, which were subsequently evaluated in a transmission electron microscope (002A-Akashi) at $60 \mathrm{kV}$. The $1 \mu \mathrm{m}$ sections were used for light microscopy after staining with toluidine blue and basic fuchsin.

Tensile strength. Immediately after harvesting, the fibres were tested for tensile strength, using a tensile tester (Zwick 1461). The initial length of the fibres was $0.5 \mathrm{~cm}$. The rate of strain was $6 \mathrm{~mm}$ per min. The mean value of six determinations was calculated.

Molecular weight. After harvesting, the fibrous capsule around the fibre was exposed to collagenase $(50 \mathrm{lU} / \mathrm{ml}$ PBS) for $2 \mathrm{~d}$. Subsequently the fibres were vacuum-dried and dissolved in dichloromethane. Determination of average molecular weight $\left(\overline{\mathrm{M}}_{\mathrm{w}}\right)$ of PLLA was performed by combined high performance gel permeation chromatography (g.p.c.) and low angle laser light scattering (I.a.l.l.s.) measurements. The g.p.c. unit, a h.p.l.c. equipped with 4 microstyragel columns (respectively $10^{5}, 10^{4}, 10^{3}$ and $500 \AA$ ). was connected with the I.a.l.I.s. apparatus and a differential refractometer.

Residual hormone determination of the fibres. Residual contents were dissolved in chloroform and the concentrations of the solutions were subsequently determined using a u.v. spectrophotometer (Unicam SP 800 ) at $247 \mathrm{~nm}$. (The molecular extinction coefficient of levonorgestrel in chloroform was $15900 \mathrm{I} \mathrm{mol}^{-1} \mathrm{~cm}^{-1}$.

In vitro release studies. Hollow fibres were filled with a $25 \%$ $(\mathrm{w} / \mathrm{w})$ dispersion of micronized ${ }^{3} \mathrm{H}$-labelled levonorgestrel (obtained from Schering, FRG), in castor oil and placed in either $45 / 55 \%(\mathrm{v} / \mathrm{v})$ ethanol/water or $30 / 70 \%$ ethanol/ water mixtures, which were then continuously shaken at $37^{\circ} \mathrm{C}$. Every fourth day a $200 \mu \mathrm{l}$ sample was taken and placed in $4 \mathrm{ml}$ Lipoluma courting liquid (Hicol) and counted by liquid scintillation, using a LKB-Wallac 1219 counter.

\section{RESULTS}

In vitro release studies using tritiated levonorgestrel (30/ $70 \%$ ethanol/water mixture) showed a near zero-order release rate over a period of more than $320 \mathrm{~d}$, resulting in a 
release rate of approx. $2 \mu \mathrm{g} / \mathrm{d}$ (Figure 3). After day 140 a slight increase in the release rate was observed, possibly due to degradation of the fibre material.

In vivo release studies using fibres, disinfected with alcohol, showed a release rate of approx. $2.4 \mu \mathrm{g} / \mathrm{d}$ resulting in a release period of over $180 \mathrm{~d}$ (Figure 4). After $\gamma$-sterilization of levonorgestrel containing fibres no zero-order release rate could be demonstrated. Apparently the $\gamma$-sterilization affects the structure of the fibre wall (by diminishing $M_{w}$ of PLLA to $1 / 3$ ) and also causes chemical modification of the levonorgestrel (Figure 11). Biodegradation of the fibre was followed by measuring the tensile strength (Figure 5) and molecular weight as a function of time (Figure 6). Tensile strength measurements performed at different implantation times showed a behaviour corresponding with the changes in $\bar{M}_{w}$. The fibrous capsule that is formed around the hollow fibre increases the tensile strength by approximately $30 \mathrm{~g}$ (as measured in a separate determination). After $\gamma$-sterilization the $\bar{M}_{w}$ immediately dropped from 159000 to 65 000: 6 months after implantation the $\bar{M}_{w}$ had further decreased to 39000 . After alcohol sterilization, a decrease in $\mathrm{M}_{\mathrm{w}}$ to 55000 was observed after $120 \mathrm{~d}$ of implantation.

Cell-biological evaluation of the 'healing process' demonstrated that the fibre surface was initially covered with granulocytes and macrophages. After $2 \mathrm{~d}$, the granu-

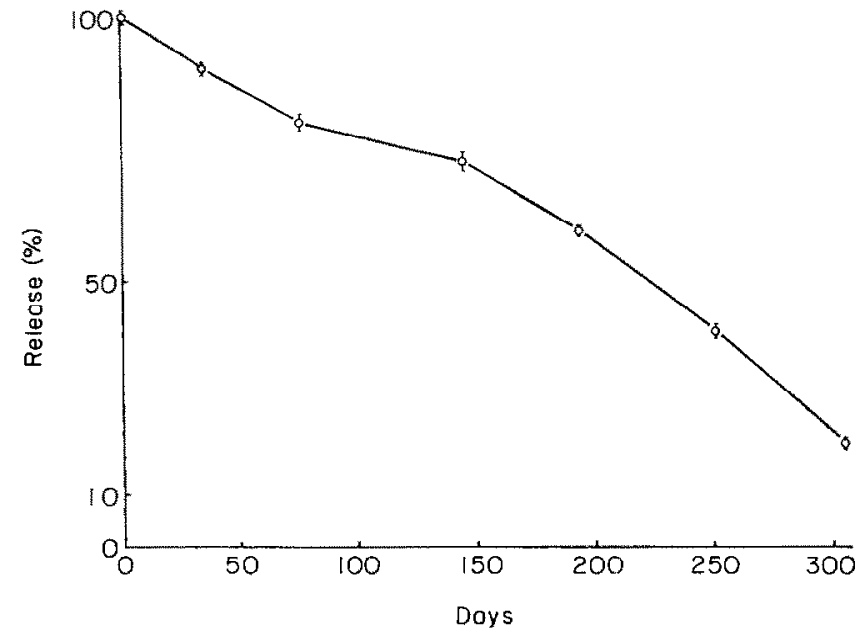

Figure 3 In vitro release of ${ }^{3} \mathrm{H}$-levonorgestrel from poly-L-lactic acid fibres in ethanol/water $(30 / 70 \%)$

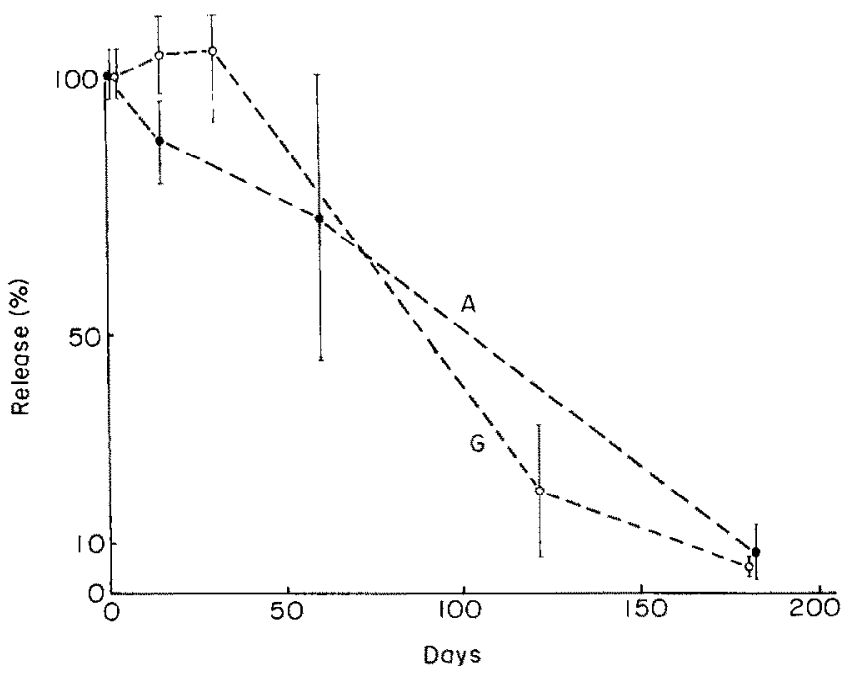

Figure 4 In vivo release of levonorgestrel from poly-i-lactic acid fibres implanted in rats, after ethanol (A) and after $\gamma-(G)$ sterilization.

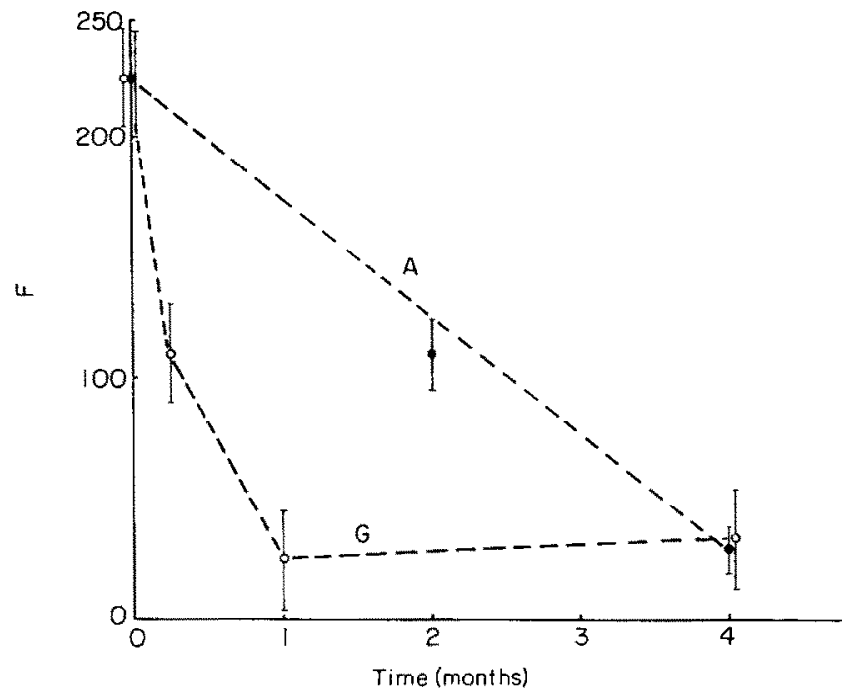

Figure 5 Tensile strength of alcohol (ethanol) (A) and $\gamma$ - (G) sterilized fibres as a function of time. F, tensile strength in grams.

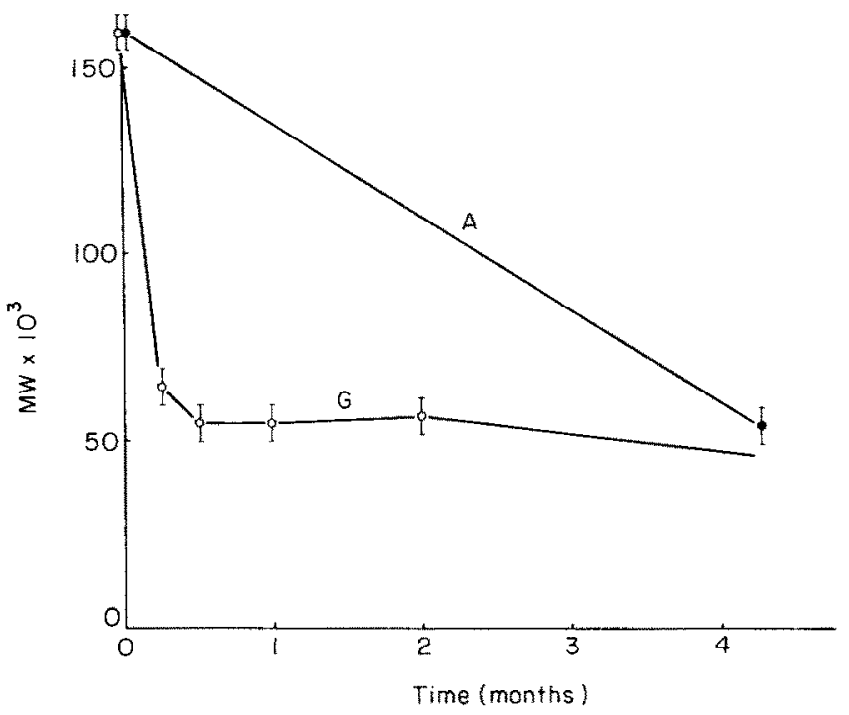

Figure 6 Molecular weight of alcohol (ethanol) (A) and $\gamma$ - (G) sterilized fibres as a function of time.

locytes disappeared and capillaries were activated to bud. At day 7 , macrophages formed a complete monolayer around the fibre. The cell membrane contacting the fibre, closely followed the smooth contours of the polymer, at a regular distance of approx. $10 \mathrm{~nm}$ (Figure 7).

The local formation of close contacts and focal adhesions could be observed. The cells were metabolically very active as judged by the amount of mitochondria, both smooth and rough endoplasmatic reticulum and Golgi apparatus (Figure 8 ). The macrophages at the cell-polymer interphase showed a remarkable appearance. At their cell membrane not facing the polymer, microvillous structures were observed, sometimes interdigitating with neighbouring cells (Figure 9).

From 2 wk on, a layer of fibroblasts was observed surrounding the macrophages. These fibroblasts started to produce a collagen sheet around the fibre, and gradually the macrophages disappeared (Figure 10). At 6 months a mature fibrous capsule was formed around the fibre, with both circularly and longitudinally arranged fibres. At places where more mechanical stress occurred, (at the lateral edges of fibres) a thicker layer could be observed. No chronic infection, foreign body reaction or the formation of giant cells was observed. 


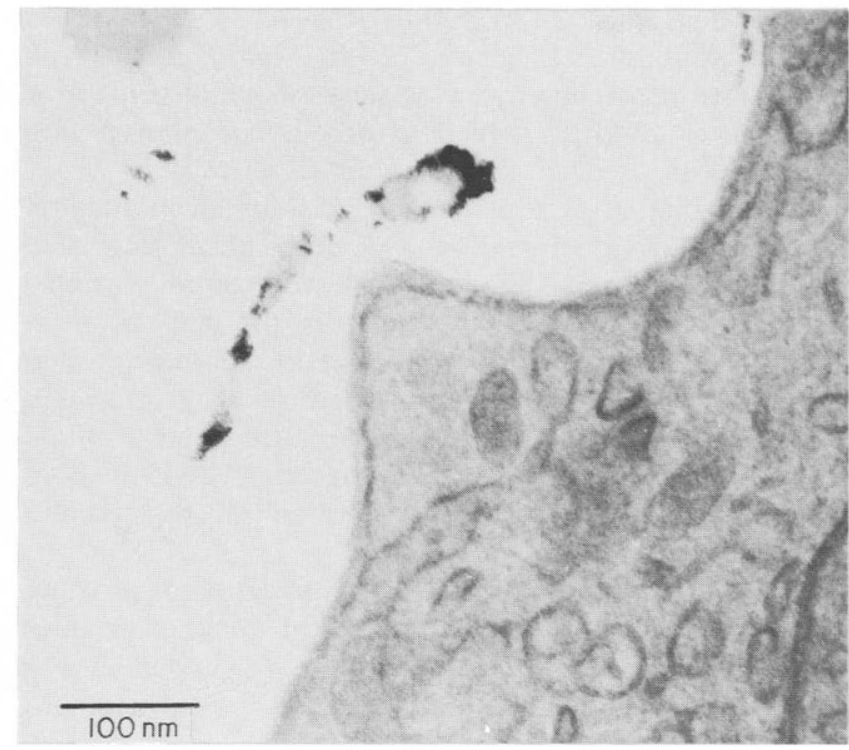

Figure 7 Macrophage at a regular distance of approx. $10 \mathrm{~nm}$ from the poly-L-lactide fibre wall.

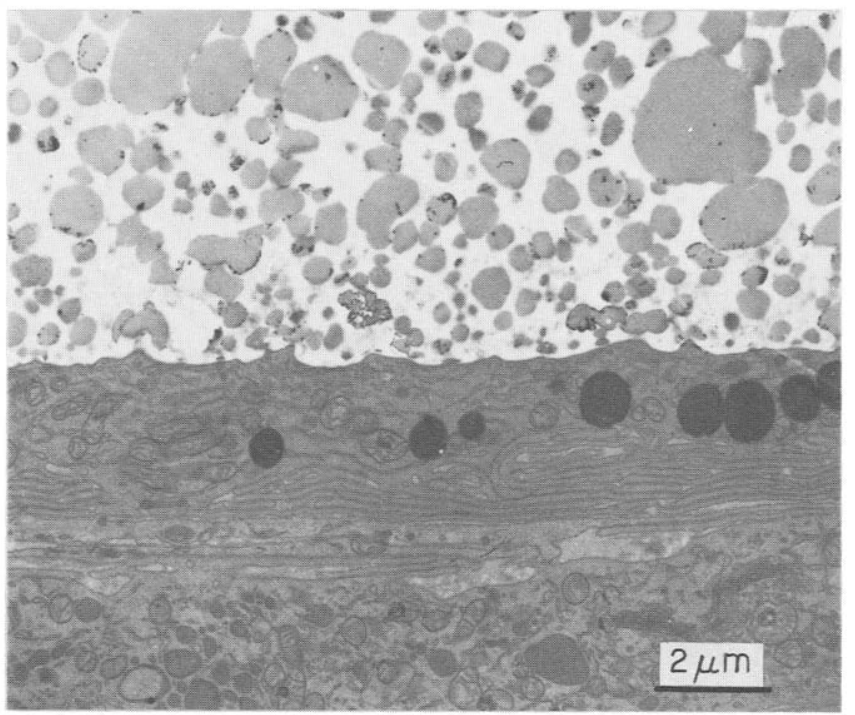

Figure 8 Active cell-polymer interface.

\section{DISCUSSION}

The results demonstrate that with our new release system both in vivo and in vitro a near zero-order release of levonorgestrel from PLLA fibres is obtained. The initial purpose which was to obtain zero-order release for 6 months is met easily.

Biodegradation of the fibre material, as monitored by tensile strength and $\bar{M}_{w}$ determinations, starts immediately after implantation. The fibres, however, retained their shape and function until the total contents had been released.

Complete degradation or fragmentation of the fibres was not observed during the time they were studied, although it was observed that from 4 wk onwards some of the fibres showed defects. The fibre parts however were surrounded by a fibrous capsule and remained in their original positions. It might be expected that breaking of the fibre would result in a significant increase in drug release rates. Only a minor increase was observed however and it was concluded that in case of defects in the fibre wall only a small area of the total surface develops where the suspension in oil is directly exposed to the fibrous capsule. This did not contribute greatly to the total release rate.

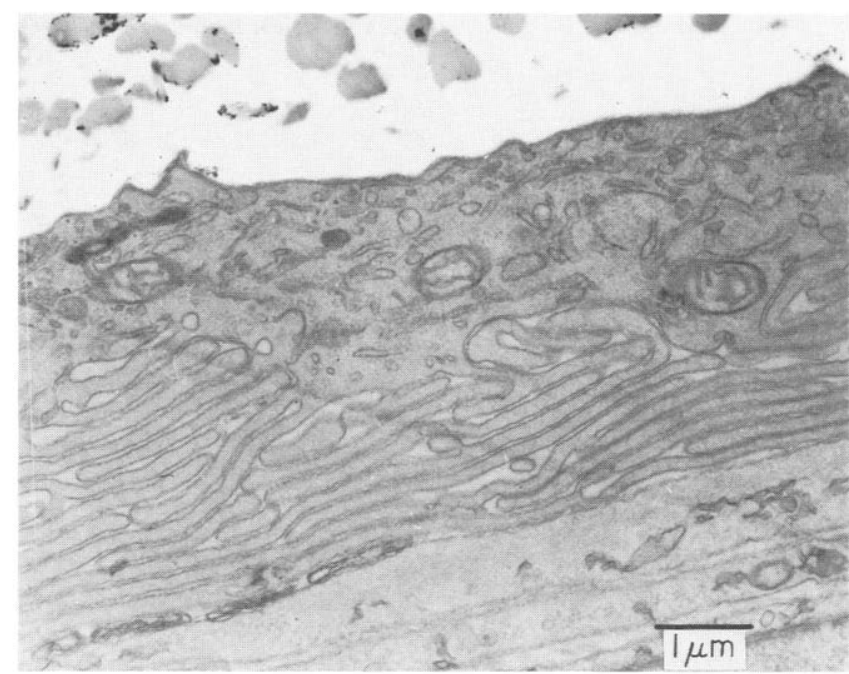

Figure 9 Microvillous structure at the side of the cell not facing the polymer.
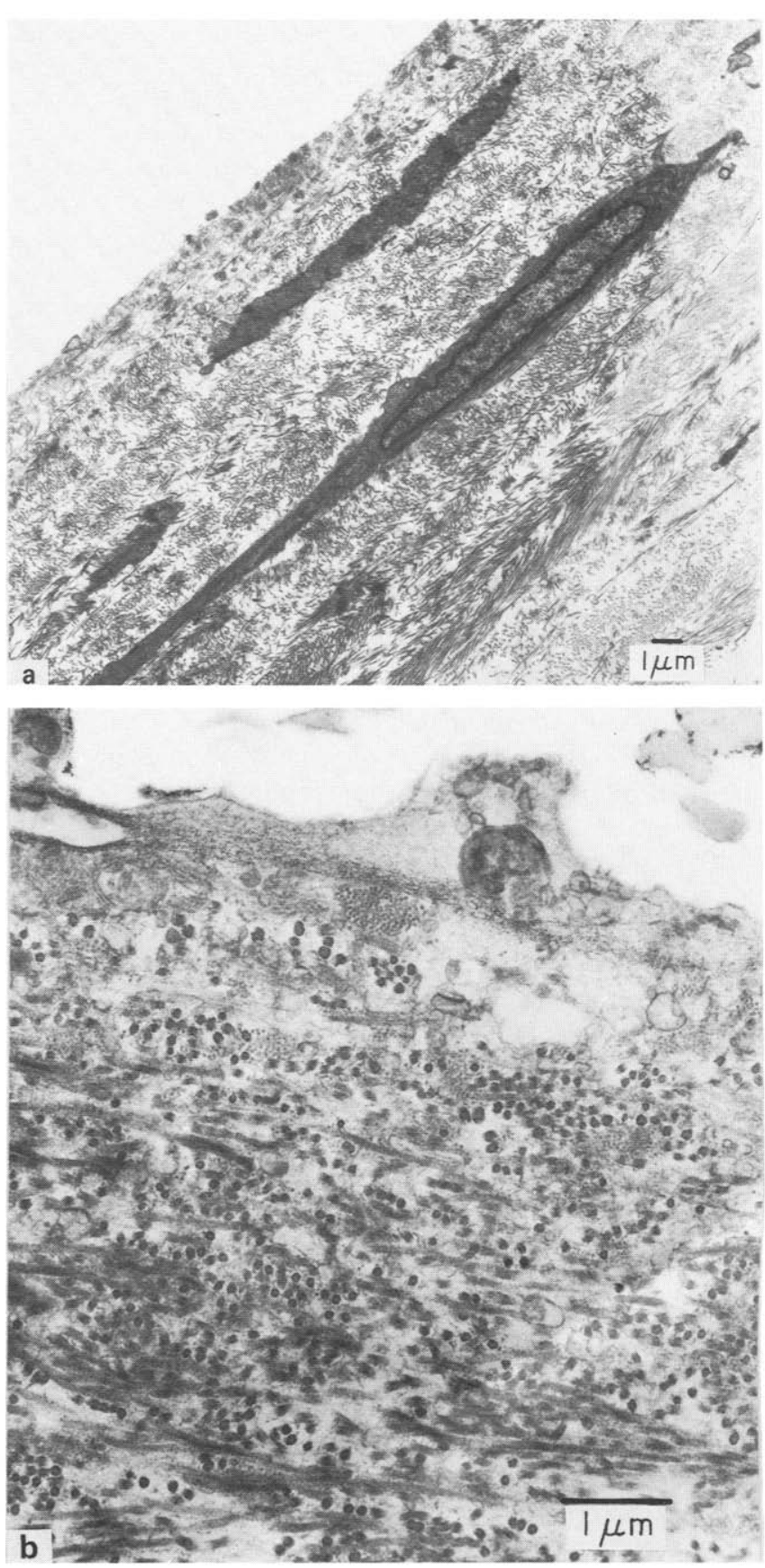

Figure 10 Collagen formation around the fibre (a) and (b) 


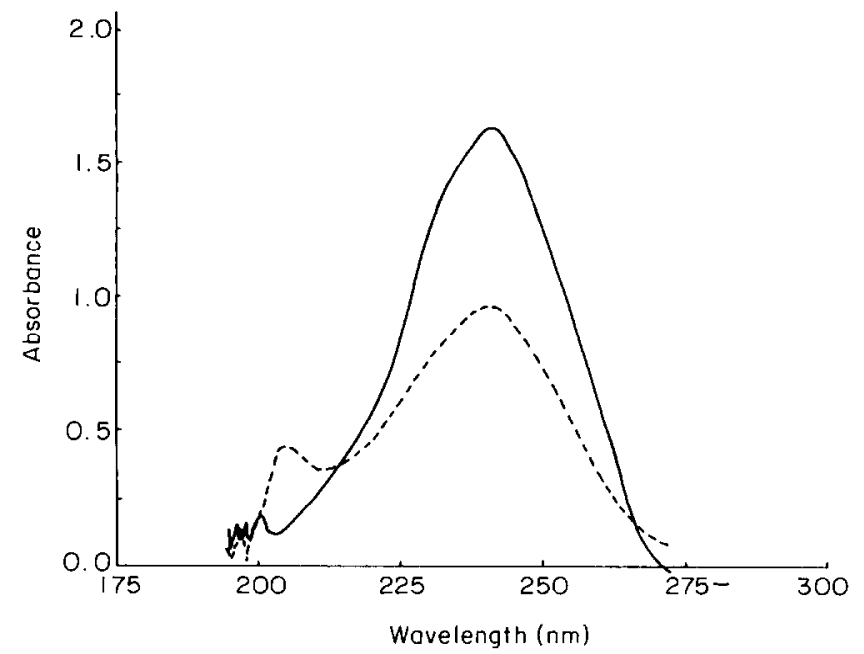

Figure 11 U.v. spectrum of levunorgestrel before (-) and after (---) $\gamma$-sterilization with $2.5 \mathrm{Mrad}$.

In vitro, a perfect zero-order release rate was observed. These determinations were performed in 30/70\% ethanol/ water mixtures and it could be expected that the in vivo release was somewhat lower since levonorgestrel dissolves better in alcohol than in water. It could also be expected that the encapsulation of the fibre might impair the zero-order rate release. However, we observed a slightly higher release in vivo, which could still be described as near zero-order, at least when the fibres were alcohol disinfected. Apparently encapsulation does not inhibit the amount of drug release significantly and does not influence the rate of release.

The cellular response to the poly-L-lactic acid fibre could be described as a very moderate foreign body reaction. which is composed of two components, a primary wound healing process and an attempt by the macrophages to engulf the foreign body. Initially a large number of neutrophilic granulocytes and a smaller number of eosinophilic granulocytes migrate towards the fibres, followed by the macrophages. This response is presumably evoked by the tissue damage induced by the implantation itself. It can be described as a primary wound healing process. After $3 \mathrm{~d}$ the granulocytes gradually disappear and macrophages cover the graft interface. These macrophages seem quite metabolically active but no degradation of the fibre could be observed as a result of their actions. Possibly, the macrophages try to engulf the foreign body, but fail to do $\mathrm{so}^{8}$. The absence of foreign body giant cells and lymphoid elements indicates that the graft can be regarded as quite inert; eventually the macrophage phagocytic activity was low and the graft did not induce a chronic inflammation ${ }^{8-10}$.

The appearance of fingerlike extensions of macrophages after $1 \mathrm{wk}$ of implantation on the side of the cell not facing the fibre has also been described by others ${ }^{11}$. Salthouse ${ }^{12}$ suggested that these structures (called lamellopodia) were involved in engulfing polymer debris and were indicative of macrophage activity. However, in our model, the polymer to be engulfed is situated at the opposite side of the cell. We therefore consicier it a foreign body induced surface enlargement. Since membrane processes in cellular metabolic activity can only take place at the side of the cell not facing the polymer this metabolic effective membrane surface may enlarge, in the way described, as a compensation mechanism.

In vitro release studies have been performed in $45 / 55 \%$ and $30 / 70 \%$ ethanol/water mixtures. Release rates were highest when more ethanol was present in the medium. The release rate in the $45 / 55 \%$ medium was approx. $12 \mu \mathrm{g} \mathrm{cm}^{-1}(24 \mathrm{~h})^{-1}$. The release rate in the $30 / 70 \%$ medium was approx. $2 \mu \mathrm{g} \mathrm{cm}^{-1}\left(24 \mathrm{~h}^{-1}\right.$ (see Figure 3). The release rate in vivo however was somewhat higher (approx. $2.4 \mu \mathrm{g} \mathrm{cm}^{-1}(24 \mathrm{~h})^{-1}$ which is not in accordance with expectations.

$\gamma$-Irradiation of the fibres filled with levonorgestrel caused not only a decrease in the $\bar{M}_{w}$ of the poly-L-lactic acid from 159000 to 65000 but the levonorgestrel was also damaged, as judged by the change in the u.v. spectrum (Figure 11). The occurrence of a shoulder at lower wavenumbers indicates the presence of low molecular degradation products of levonorgestrel. Moreover, after $\gamma$-sterilization, the in vivo release rate was not of zero-order. When the fibre is filled with the drug after it has been sterilized, the problem does not occur.

Alternative applications for the hollow fibres are now being considered, such as cytostatics, antibiotics or hormones (e.g. LH-RH). The fibre wall has to be adapted for these purposes.

\section{CONCLUSION}

The biodegradable hollow fibre of poly-L-lactic acid evokes only a very moderate foreign body reaction and is therefore a suitable device for the release of drugs over a long period of time.

\section{ACKNOWLEDGEMENTS}

We gratefully acknowledge the help of I. Stokroos for drawing the Figures, D. Huizinga for photographic assistance and Mrs M.P. Schakenraad-Dolfing for typing the manuscript.

\section{REFERENCES}

1 Leong, K.W., Brott, B.C. and Langer, R., Bioerodible polyanhydrides as drug-carrier matrices. I: Characterization, degradation and release characteristics, J. Biom. Mater. Res. 1985, 19, 941-955

2 Heller, J., Controlled drug release from poly(ortho-esters) a surface eroding polymer, J. Contr. Release 1985, 2, 167-177

3 Beck, L.R., Ramos, R.A., Flowers, C.E., Lopez, G.Z., Lewis, D.H. and Cowsar, D.R., Clinical evaluation of injectable biodegradable contraceptive system. Am. J. Obstet. Gynecol. 1985, 140, 799-806

4 Kruisbrink, J., van der Woude, T.P., Boer, G.J. and Mirmiran, M., Manipulation of vasopressin level in the cerebrospinal fluid of the rat by means of an easily interchangeable controlled-deliven Accure mini-device, J. Neurosci. Meth. 1986, 17, 103-108

5 Albers, J.H.M., Rieke, J.C., Olijslager, J., Griedanus, P.J., Eenink, M.J.D. and Feyen, J., Subdermal drug delivery with a biodegradable hollow fiber device, Proc. Int. Symp. Controlled Release Bioact. Mat. 1984, 11, 80-81

6 Eenink, M.J.D., Albers, J.H.M., Rieke, J.C., Olijslager, J., Griedanus, P.J. and Feyen, J., Biodegradable hollow fibers for the controlled release of drugs, Proc. Int. Symp. Controlled Release Bioact. Mat. $1985,12,49-50$

7 Schakenraad, J.M., Eenink, M.J.D., Oosterbaan, J.A., Feyen, J., Potman, W., Olijslager, J., Griedanus, P.J., Molenaar, I. and Nieuwenhuis, P., Biodegradable hollow fibers for the controlled release of drugs; a preliminary report on tissue reaction, in Advances in Biomaterials, Vol. 7. Elsevier, Amsterdarn 1987, 637-642

8 Rae.T., The macrophage response to implant materials - with special reference to those used in orthopedics, in CRC Critical Reviews in Biocompatibility, Vol 2, 1986, pp 97-126

9 Hirsh, B.C. and Johnson, W.C., Concepts of granulomatous inflammation, Int. J. Dermatol. 1984, 33, 90-100

10 Behling, C.A. and Spector, M., Quantitative characterization of cells at the interface of long-term implants of selected polymers, J. Biom. Mater. Res. 1986, 20,653-666

11 Matlaga, B.F. and Salthouse, T.N., Ultrastructural observations of cells at the interface of a biodegradable polymer: Polyglactin 910, J. Biom. Mater. Res. 1983, 17, 185-197

12 Salthouse, T.N., Some aspects of macrophage behaviour at the implant interface, J. Biom. Mater. Res. 1984, 18, 395-401 